D.O.I: $10.3895 /$ gi.v10i1.1703

\title{
EVIDENCIAÇÃO DOS GASTOS AMBIENTAIS NUMA EMPRESA PRODUTORA DE BIOENERGIA: UM ESTUDO DE CASO
}

\section{DISCLOSURE OF ENVIRONMENTAL EXPENDITURES IN A COMPANY PRODUCING BIOENERGY: A CASE STUDY}

\author{
Graciela Arcanjo da Costa ${ }^{1}$; Maria Aparecida Farias de Souza Nogueira ${ }^{2}$; Marli da Silva Garcia ${ }^{3}$ \\ ${ }^{1}$ Universidade Federal da Grande Dourados- UFGD \\ cielyarcanjo@hotmail.com \\ ${ }^{2}$ Universidade Federal da Grande Dourados- UFGD \\ marianogueira@ufgd.edu.br \\ ${ }^{3}$ Universidade Federal da Grande Dourados- UFGD \\ marliggarcia@gmail.com
}

\begin{abstract}
Resumo
Este trabalho teve como objetivo geral evidenciar os gastos ambientais de uma empresa produtora de bioenergia, com o intuito de demonstrar o grau de consciência e preocupação em relação ao meio ambiente, e enfatizar a importância da contabilidade ambiental na identificação, registro e na mensuração dos fatos ambientais da empresa. Neste trabalho utilizou-se de metodologia de pesquisa documental, exploratória e quali-quantitativa. Por meio de dados disponibilizados em relatório da empresa estudada foi possivel calcular alguns indicadores de desempenho ambientais, visto que o instrumento de pesquisa foi baseado em análise de dados de indicadores. Como observado, a evidenciação de gastos ambientais é uma aliada importante para construir ou melhorar a imagem de uma empresa perante o mercado e a sociedade, que cada vez mais, tornamse exigentes. Porém, isso não será possível se a empresa não tiver uma contabilidade ambiental que forneça informações úteis para a tomada de decisão, principalmente, em relação à área ambiental.
\end{abstract}

Palavras chave: contabilidade ambiental; indicadores de desempenho ambientais; bioenergia.

\section{Introdução}

A cobrança de escolhas inovadoras e novas formas de pensar são uns dos principais desafios do desenvolvimento sustentável. Ao mesmo tempo em que a tecnologia contribui para o crescimento econômico, ela também ajuda a solucionar danos ao meio ambiente, causados por esse mesmo crescimento. Cada vez mais novos conhecimentos e inovações em tecnologia, em gestão e políticas públicas, desafiam as organizações a fazerem escolhas em suas atividades operacionais que causam um menor impacto ao meio ambiente (Global Reporting Iniciative-GRI, 2000-2006).

A transparência sobre os impactos econômicos, sociais e ambientais é um elemento essencial para eficácia nas relações entre as organizações e seus Stakeholders, isto é, usuários "a 
transparência em relação à sustentabilidade das atividades organizacionais é do interesse de diferentes públicos da empresa, incluindo mercado, trabalhadores, organizações não governamentais, investidores, contadores etc." (Global Reporting Iniciative - GRI, 2000-2006, p.2).

Para atender aos stakeholders, as empresas precisam, além de relatar suas ações sobre os impactos econômicos, sociais e ambientais, evidenciar seus gastos, para que fique visível o grau de consciência e preocupação em relação ao meio ambiente.

O desenvolvimento do mercado, a competição acirrada entre as empresas, a exigência dos consumidores por produtos sustentáveis, obrigam as empresas a tomarem atitudes mais conscientes no que se refere ao meio ambiente.

De acordo com Nasário (2002 apud CUNHA et al 2010), quando há uma melhor conscientização da valorização do meio ambiente, surge uma necessidade de conciliação entre o desenvolvimento econômico e a preservação ambiental. Então, entra a contabilidade ambiental como uma vantagem competitiva, pelo fato de identificar, mensurar, e registrar os fatos internos e externos da organização.

Não basta apenas promover ações ambientais, é preciso também divulgar, por meio de relatórios, o reflexo dos fatos ambientais no patrimônio da empresa, ou seja, evidenciar os gastos ambientais para que fique visível à sociedade.

Diante do exposto a problemática a ser investigada é: como a evidenciação de gastos ambientais pode ajudar a empresa a melhorar sua competitividade e ainda sua imagem, perante a sociedade?

\section{Contabilidade e contabilidade ambiental}

A contabilidade é uma ciência que tem como objetivo fornecer informações úteis aos usuários internos e externos (stakeholders), no que se refere aos fatos econômicos que possam impactar o patrimônio da empresa. Os chamados stakeholders são os usuários que dependem dessas informações para a tomada de decisão, pois por meio de relatórios contábeis é demonstrada a real situação da empresa (CUNHA et al, 2010).

Para Scarpin et al (2010), a contabilidade se apresenta como prestadora de contas à investidores, credores, governo e a outros interessados, dando possibilidades de avaliarem criteriosamente o estado patrimonial, econômico e social da organização. Como diz Santos et al (2001, p. 91), "atualmente, a contabilidade é considerada um sistema de informações que tem como objetivo auxiliar o gerenciamento das entidades para que essas possam garantir sua continuidade".

A consciência ambiental, a transformação dos pensamentos e ações da sociedade contribuiu para o surgimento da necessidade de se obter informações ambientais na contabilidade das empresas. Foi então, que apareceu dentre as várias especializações da contabilidade, a contabilidade 
ambiental que desde 1997 vem se desenvolvendo, e aos poucos sendo reconhecida pelas organizações (PAIVA, 2009).

Segundo Ferreira (2009, p. 59), a “...contabilidade ambiental [...] tem como objetivo demonstrar em termos econômicos, qualquer ação de uma entidade que afete seu patrimônio, no que se refere às práticas ambientais".

A contabilidade ambiental incentiva às organizações a evidenciar os gastos ambientais de forma transparente, com "um grau de preocupação e amadurecimento elevados, demonstrando a existência de uma consciência ambiental desenvolvida”, como frisa Paiva (2009, p. 47). Assim a organização que começar a evidenciar seus gastos ambientais de forma que fique visível a sociedade, terá uma grande vantagem competitiva no mercado.

Tinoco e kraemer (2008) enfatizam a importância de se ter práticas ambientais introduzidas nas organizações, pois segundo eles, isso poderá proporcionar redução de custos através da melhoria da eficiência dos processos, a redução de consumos, como (matéria-prima, água, energia), além da minimização do tratamento de resíduos e efluentes e diminuição de prêmios de seguros, multas etc.

Portanto, a contabilidade ambiental é de grande importância, pois ela auxilia no processo de comunicação entre as empresas e a sociedade na defesa do meio ambiente, identificando e oferecendo informações úteis para controlar impactos ambientais, além de fortalecer a imagem de uma empresa, demonstrando a socialmente responsável (BORGES et al, 2010).

\subsection{Protocolo de Kyoto}

É crescente o uso do termo sustentabilidade pelas pessoas, pois não há como ignorar a necessidade de preservação e recuperação do meio ambiente. No entanto, como diz Ribeiro (2005, p. 7), "a degradação do meio natural em decorrência das ações humanas atingiu níveis tão elevados que as ações preventivas e de recuperação se tornam imperativas”. Ainda segundo a autora, ações locais isoladas, já não basta, são necessárias atitudes de âmbito global.

Como exemplo de uma atitude mundial, pode-se citar o Protocolo de Kyoto (1997), que uniu mais de 55 países comprometidos a reduzir as emissões de gases que provocam o efeito estufa. Para o cumprimento dessa redução, poderão ser utilizados três mecanismos: Execução Conjunta (Joint Implementation), Comércio de emissões (Emissions Trade) e Mecanismo de Desenvolvimento Limpo (MDL) (RIBEIRO, 2005, p. 9).

O MDL foi adaptado para os países em desenvolvimento, dos quais o Brasil faz parte, para que estes possam receber financiamentos de projetos custeados pelos países desenvolvidos. Assim, os países em desenvolvimento terão recursos para se chegar a um desenvolvimento sustentável, diminuindo a emissão de gases de efeito estufa e proporcionando oportunidades para os países 
desenvolvidos compensarem a poluição que produzem e, que por muitas razões não conseguem eliminar (RIBEIRO, 2005).

As empresas que se utilizam de práticas sustentáveis buscam fazer a evidenciação das mesmas por meio de indicadores.

\subsection{Evidenciação e indicadores}

As empresas para serem inseridas no mercado mundial, precisam demonstrar preocupação e um certo amadurecimento em relação ao meio ambiente, ou seja, devem estar conscientes da necessidade de preservação e recuperação ambiental, pois, para inserção no ambiente mundial é imprescindível o cumprimento de alguns requisitos ambientais, sendo a evidenciação a maneira de torná-los notórios a sociedade (PAIVA, 2009).

De acordo com Borges et al, (2010), a evidenciação é uma avaliação das informações ambientais demonstradas, além de agregar valor à organizações, ela promove a transparência das informações a todos os stakeholders, e pode ser feita de diversas formas, como diz Kosztrzepa, 2004 apud Borges 2010, p. 406, "... das quais sem dúvida irão beneficiar-se as empresas e os usuários das informações contábeis a tomarem decisões mais confiáveis e seguras sobre a organização."

Segundo Paiva (2009, p. 47), quando as empresas adotam a prática de medidas preventivas e corretivas podem, além de evitar multas e complicações judiciais, conservam suas imagens e patrimônios e evitam crises de credibilidade. A preocupação com o meio ambiente muda a forma de olhar da sociedade, e exerce um grande papel, pois, assim, a empresa mantém seus clientes e atraem novos consumidores.

De acordo com Ribeiro, 1992 apud Paiva, 2009, "a evidenciação dos desembolsos relacionados ao meio ambiente é de relevante importância para atender as necessidades atuais, ou seja, a informação como instrumento de combate a crescente evolução dos níveis de poluição e seus efeitos nocivos".

\subsubsection{Modelo de evidenciação}

O modelo de evidenciação procura identificar os gastos ambientais das empresas, com uma separação básica entre preventivos e remediáveis, no entanto, existem alguns gastos que são irremediáveis e irrecuperáveis. De acordo com o grau de evolução das empresas, no que se refere à evidenciação de gastos ambientais e sua forma de evidenciá-los, foi elaborado um quadro que pode servir como um referencial de acompanhamento das atividades ambientais de uma determinada empresa (PAIVA, 2009). 


\subsection{Indicadores de desempenho ambientais}

Nos países como, a Alemanha, Estados Unidos, Canadá, Nova Zelândia, Bélgica, Suíça, Austrália e Inglaterra e entre outros, há indústrias que fazem o uso dos Environmental Performance Indicators (EPI) (Indicadores de desempenho ambientais), para controlar e divulgar medidas de emissão de resíduos na natureza, oriundos de seus processos produtivos. Os EPIs descrevem cada elemento de forma individualizada, como por exemplo, a emissão de gás carbônico ou qualquer outro poluente. Essa forma individualizada de tratamento admite que as empresas interessadas em controlar a emissão façam separadamente, ou seja, isolando o controle de cada espécie de emissão (PAIVA, 2009).

De acordo com Tinoco e Kraemer (2008, p. 279), os indicadores de desempenho ambiental “... sintetizam as informações quantitativas e qualitativas que permitem a determinação da eficiência e efetividade da empresa, de um ponto de vista ambiental, em utilizar os recursos disponíveis".

Paiva (2009) propõe o modelo apresentado propõe a complementação das informações obtidas a partir dos indicadores existentes, proporcionando uma visão mais ampla do direcionamento dos recursos da empresa nas atividades ambientais, seja na prevenção, ou na remediação.

Os números obtidos por meio do modelo indicador de desempenho ambientais - emissão de resíduos, constituem uma poderosa ferramenta no controle das emissões de resíduos se forem bem elaborados, interpretados e utilizados. O protocolo de Kyoto que propõe o controle e a redução da emissão de gases poluentes possui para tal, os indicadores de desempenho ambientais como base de mensuração (PAIVA, 2009).

Segnestam (1999 apud Paiva, 2009) afirma que para a formulação dos Indicadores de Desempenho Ambientais, é necessária a utilização de alguns parâmetros, como diz Tinoco e Kraemer (2008, p.280), "parâmetro corresponde a uma grandeza que pode ser medida com precisão ou avaliada qualitativamente/quantitativamente, e que se considera relevante para a avaliação dos sistemas ambientais, econômicos, sociais e institucionais". São eles: número limitado, clareza da proposição, coleta realista ou custo de desenvolvimento, clara identificação dos relacionamentos causais, alta qualidade e confiabilidade, escala espacial e temporal apropriada e objetivos e linhas básicas.

Martins e Assaf Neto (1993 apud Paiva, 2009) afirmam que para desenvolver um estudo sobre o seu desempenho, a empresa precisa comparar os indicadores com os de períodos anteriores, com os de padrões estabelecidos e com índices de empresas do mesmo ramo e padrões do setor de atividade. 
Paiva (2009) demonstra alguns indicadores elaborados com sua interpretação, descrita conforme na Figura 1.

Figura 1 - Proposição de eco-indicadores contábeis.

\begin{tabular}{|c|c|c|c|}
\hline Índice & Formulação & Relação causal & Reflexo \\
\hline $\begin{array}{l}1^{\mathrm{a}}-\text { Investimentos } \\
\text { ambientais gerais }\end{array}$ & $\begin{array}{l}\text { Investimentos em } \\
\text { prevenção/Ativos } \\
\text { totais }\end{array}$ & $\begin{array}{l}\text { Indica a proporção de ativos } \\
\text { ambientais adquiridos no período } \\
\text { e os ativos totais da empresa. }\end{array}$ & $\begin{array}{l}\text { Reflete o posicionamento da } \\
\text { empresa frente à questão ambiental, } \\
\text { de forma ampla. }\end{array}$ \\
\hline $\begin{array}{l}2^{\mathrm{a}}-\quad \text { Investimentos } \\
\text { ambientais } \\
\text { operacionais }\end{array}$ & $\begin{array}{l}\text { Investimento em } \\
\text { prevenção/ Ativo } \\
\text { imobilizado }\end{array}$ & $\begin{array}{l}\text { Revela a evolução dos } \\
\text { investimentos em prevenção em } \\
\text { relação parque fabril. }\end{array}$ & $\begin{array}{l}\text { Demonstra a preocupação com a } \\
\text { qualidade de seu parque fabril. }\end{array}$ \\
\hline $\begin{array}{lr}3^{\text {a }}-\text { Diminuição do } \\
\text { patrimônio } & \text { dos } \\
\text { acionistas } & \text { em } \\
\text { decorrência } & \text { de } \\
\text { fatores ambientais }\end{array}$ & $\begin{array}{l}\text { Perdas ambientais / } \\
\text { Patrimônio liquido }\end{array}$ & $\begin{array}{l}\text { Mostra o percentual de seu } \\
\text { patrimônio que está sendo } \\
\text { diminuído em função de perdas } \\
\text { ambientais. }\end{array}$ & $\begin{array}{l}\text { Reflete o grau de cuidado com as } \\
\text { operações, assim como o reflexo } \\
\text { direto na alteração do patrimônio. }\end{array}$ \\
\hline $\begin{array}{lr}4^{\mathrm{a}} \quad- & \text { Perdas } \\
\text { ambientais } & \text { da } \\
\text { empresa } & \end{array}$ & $\begin{array}{l}\text { Perdas ambientais / } \\
\text { Ativo total }\end{array}$ & $\begin{array}{l}\text { Relaciona o quanto, em termos } \\
\text { percentuais, as perdas } \\
\text { significaram sobre os bens e } \\
\text { direitos que a empresa dispunha } \\
\text { no período. }\end{array}$ & $\begin{array}{l}\text { Reflete o grau de conscientização } \\
\text { mediante desastres ambientais. }\end{array}$ \\
\hline $\begin{array}{ll}5^{\mathrm{a}} \quad- & \text { Custos } \\
\text { ambientais } & \\
\text { operacionais } & \end{array}$ & $\begin{array}{l}\text { Custos ambientais / } \\
\text { Receitas } \\
\text { operacionais }\end{array}$ & $\begin{array}{l}\text { Indica o quanto os custos } \\
\text { ambientais apropriados no } \\
\text { período representam nas receitas } \\
\text { operacionais }\end{array}$ & $\begin{array}{l}\text { Demonstra os investimentos da } \\
\text { empresa na qualidade ambiental de } \\
\text { seus produtos e como essa relação } \\
\text { pode afetar seu resultado. }\end{array}$ \\
\hline 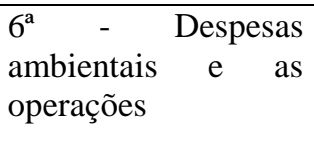 & $\begin{array}{l}\text { Despesas ambientais } \\
\text { / Receitas } \\
\text { operacionais }\end{array}$ & $\begin{array}{l}\text { Demonstra o quanto foi } \\
\text { consumido de despesas, } \\
\text { favorecendo o meio ambiente na } \\
\text { geração de receitas operacionais. }\end{array}$ & $\begin{array}{l}\text { Revela a relação entre a } \\
\text { conscientização ambiental da } \\
\text { empresa e suas atividades de } \\
\text { comercialização. }\end{array}$ \\
\hline $\begin{array}{lr}7^{\mathrm{a}}- & \text { Prevenção e } \\
\text { valor } & \text { adicionado } \\
\text { gerado } & \end{array}$ & $\begin{array}{l}\text { Gastos totais com } \\
\text { prevenção / Valor } \\
\text { adicionado total }\end{array}$ & $\begin{array}{l}\text { Relaciona os gastos em } \\
\text { prevenção com os valores } \\
\text { adicionados. }\end{array}$ & $\begin{array}{l}\text { Reflete como a empresa está } \\
\text { administrando na prevenção de } \\
\text { problemas ambientais face ao valor } \\
\text { adicionado por suas operações. }\end{array}$ \\
\hline $\begin{array}{l}8^{\mathrm{a}}-\text { Remediação e } \\
\text { prevenção }\end{array}$ & $\begin{array}{l}\text { Gastos com } \\
\text { remediação / Gastos } \\
\text { com prevenção }\end{array}$ & $\begin{array}{l}\text { Indica a relação entre remediação } \\
\text { e prevenção. }\end{array}$ & $\begin{array}{l}\text { Revela a postura da empresa em sua } \\
\text { relação com o meio ambiente. }\end{array}$ \\
\hline
\end{tabular}

Fonte: Paiva (2009, p.136)

\subsection{Bioenergia}

A bioenergia é uma promissora alternativa que pode ser usada tanto para gerar energia elétrica por meio de gaseificação e pirólise quanto para produzir combustível líquido (Karp \&Shield 2008 apud Souza 2011). A energia pode ser produzida em pequenas ou em grandes quantidades e pode ser gerada em quase todo lugar que possua um mínimo de condições para a concretização da síntese da vida vegetal (MOREIRA, 2007).

Várias espécies de plantas cultivadas com potencial de fonte de bioenergia, tais como álamo (Populus ssp.), salgueiro (Salix ssp.), eucalipto (Eucaliptus ssp.), milho (Zea mays), miscantus (Miscanthus $x$ giganteus), Switchgrass (Panicum virgatum) e cana-de-açúcar (Saccharum ssp.) tem sido estudadas. Porém, no Brasil a cana-de-açúcar é a planta mais utilizada em pesquisas que envolvem o bioetanol (CORTEZ, 2010 apud SOUZA, 2011). 
A cana-de-açúcar se adapta totalmente ao clima tropical (Figueiredo, 2008 apud Souza, 2011). Ela é selecionada para produzir grandes quantidades de sacarose e pequenas quantidades de fibra (Landell \& Bressiani, 2010 apud Souza, 2011). Por isso, ao longo dos anos sua produtividade tem aumentado em 60\%, principalmente entre 1980 e 2005, o que resultou um acréscimo de quase 100\% na produção de etanol (LEAL et al, 2010 apud SOUZA, 2011).

Conforme Moreira (2007, p.44), "a bioenergia é o fruto da terceira era técnica, em que estamos bem entrados e da qual o biocombustível já aparece como símbolo, assim como o petróleo e o automóvel simbolizavam a era técnica da segunda revolução industrial." Ainda segundo o autor, a bioenergia é parte de um plano maior que a biorrevolução, e é a epicentro da terceira revolução industrial.

Sendo assim, a bioenergia, o complexo agroindustrial, a bioindústria, o transporte movido a biocombustível são ligações da biorrevolução, cujo termo, exprime uma modificação nas formas de organização, da pecuária, das atividades industriais, do sistema de transporte e das fontes e formas de transmissão de energia e do acondicionamento do espaço no futuro-presente (MOREIRA, 2007, p. 45).

\subsubsection{A importância da bioenergia}

A procura mundial por energia vai crescer a uma média de $1,6 \%$ ao ano até 2030 , a causa desse aumento é o crescimento do consumo energético dos países em desenvolvimento. Já não tem como negar a influência do homem no aquecimento global e a necessidade de alívio nas alterações climáticas. Porém, pode-se dizer que a bioenergia como uma fonte renovável de energia, está sendo usada para abrandar essas alterações, utilizada em transportes e na geração de energia elétrica (IEA, 2006 apud CASTRO e DANTAS, 2008).

Segundo Castro e Dantas (2008), a bioenergia pode ser explicada como energia solar aprisionada por se originar nos processos de fotossíntese; já a biomassa na qualidade de matéria orgânica, foi uma das primeiras fontes de energia utilizada pelo homem. Porém com a introdução de combustíveis fósseis na matriz energética e a utilização de tecnologias mais eficientes, ela ficou em segundo plano.

O setor que mais utiliza a energia oriunda da bioenergia é o de transporte, por ser inviável tecnologicamente e economicamente, a substituição de combustíveis fósseis por outros tipos. Assim, seja o etanol usado como combustível ou misturado à gasolina e o biodiesel misturado ao diesel, contribuem para redução das emissões dos gases de efeito estufa por parte do setor de transporte, representando aproximadamente $30 \%$ do consumo de energia (CASTRO e DANTAS, 2008). 
O Brasil está atrás apenas dos Estados Unidos, na produção de etanol, ocupando assim a posição de segundo maior produtor mundial de etanol, com participação de 32,4\% do volume total produzido em 2004 (15 bilhões de litros), depois vem a China com (8,9\%), União Europeia (5,3\%) e a Índia (4\%) (VIAN e RIBEIRO, 2008).

Para Castro e Dantas (2008, p. 02), além de produzir biocombustíveis, " ... a bioenergia é uma fonte energética que pode ter importante participação na matriz elétrica mundial". E ainda segundo o autor, a biomassa pode gerar energia elétrica a partir de resíduos agrícolas, resíduos florestais, resíduos urbanos e até por meio de dejetos de animais.

Portanto, além de contribuir para a redução das emissões de gases de efeito estufa, a utilização de resíduos para geração de bioeletricidade pode apresentar um custo inferior ao custo de outras fontes renováveis. Ainda, há casos em que a bioeletricidade, "... é produzida a partir do eficiente processo de co-geração em processos que demandam energia térmica e elétrica de forma simultânea, como é o caso das usinas sucroalcooleiras brasileiras" (CASTRO e DANTAS, 2008, p. 03).

\section{Metodologia}

Neste trabalho utilizou-se o tipo de pesquisa exploratório e quantitativo, o instrumento de pesquisa baseado em indicadores por meio de análise de dados estatísticos com coletas de dados obtidas por meio de documentos. Caracterizou-se por meio de análises dos dados e indicadores.

Segundo Gil (2009 apud Lima, 2012), um indivíduo em um contexto definido se refere a uma unidade-caso. Ainda de acordo com o autor, a definição de caso é ampla e pode ser entendida como uma família, ou um grupo social, um pequeno grupo, uma comunidade, um papel social, uma organização, uma nação ou até mesmo toda uma cultura. O caso desse trabalho é uma empresa produtora de bioenergia, a ETH e o estudo refere-se à análise dos indicadores de desempenho ambientais com base nos relatórios anuais 2010/2011 e 2011/2012 da empresa em questão.

A ETH É uma empresa do grupo Odebrecht, fundada em 2007, possui nove unidades agroindustriais. Juntas, essas unidades somam uma capacidade de moagem de 35 milhões de toneladas de cana, com previsão de produção em 2014, de 3 bilhões de litros de etanol e $2.700 \mathrm{GWh}$ de energia elétrica a partir da biomassa.

A empresa apresentou seu primeiro relatório anual, depois de apenas quatro anos de existência, seguindo as diretrizes GRI (Global Reporting Iniciative). Reconhece a importância de relatar seus desempenhos econômicos, sociais e ambientais, sejam eles, satisfatórios ou não.

O estudo aqui selecionado refere-se à evidenciação dos gastos ambientais de uma empresa produtora de bioenergia, para mostrar o grau de preocupação e amadurecimento da empresa em relação ao meio ambiente, ou seja, se esta tem contribuído para preservação e recuperação do meio 
ambiente.

Para se alcançar os objetivos foram feitas análises de alguns indicadores de desempenho ambientais, usando como dados o relatório anual da empresa em questão. Os indicadores são: quantificação dos gastos em suas várias categorias, indicadores de desempenho ambientais emissões de resíduos e proposição de eco-indicadores contábeis.

A Tabela 1 traz informações que ajudam a identificar o relacionamento entre empresa e meio ambiente, de forma a quantificar os gastos em suas diversas categorias, por período e de maneira resumida (PAIVA, 2009).

A linha investimentos demonstra os valores que foram adicionados aos ativos imobilizados ambientais durante o período. Os investimentos em ativos são para a prevenção de danos ambientais. Porém, pode ocorrer desses mesmos investimentos servirem para remediar um dano que já estava acontecendo, e que a empresa é obrigada a evitar, seja por uma ordem legal ou por qualquer outro motivo (PAIVA, 2009).

\begin{tabular}{ccccccc}
\multicolumn{7}{c}{ Tabela 1 - Gastos com prevenção, remediação e os irremediáveis } \\
\hline \multicolumn{7}{c}{$2010 / 2011$} \\
\hline Gastos & Prevenção & Remediação & Irremediáveis & Prevenção & Remediação & Irremediáveis \\
Investimentos & $1.661 .100,60$ & & - & $4.849 .800,0$ & - & - \\
Custos & 23.201 .521$, & 19.254 .621$, & - & 27.168 .900$, & - & - \\
$\begin{array}{c}\text { Despesas } \\
\text { Perdas (geração } \\
\text { de novos }\end{array}$ & $15.000,00$ & - & - & $68.400,00$ & - & - \\
passivos) \\
$\begin{array}{c}\text { Perdas } \\
\begin{array}{c}\text { (Desvalorização } \\
\text { de ativos) }\end{array}\end{array}$ & - & - & - & - & - & - \\
\hline
\end{tabular}

Fonte: Da autora, adaptado de Paiva (2009) - Dados do relatório anual (2010/2011 e 2011/2012) da ETH

Os custos são voltados para a prevenção, e não para a remediação. Podem revelar-se de forma explícita ou oculta, cabe aos gestores identificá-los e associá-los com eventos ambientais. Já as despesas, podem proceder de treinamentos preventivos em todos os níveis da empresa, como os referentes a novos processos e programas de educação/conscientização, na manutenção, cuidado e preservação de áreas de risco. Tinoco e Kraemer (2008), ultimamente, os custos das empresas em proteção ambiental têm aumentado rapidamente com a crescente e mais exigente regulamentação ambiental, em decorrência da crescente fiscalização feita pela sociedade.

$\mathrm{Na}$ linha perdas por geração de novos passivos são classificadas as multas, oriundas de degradação ao ambiente, o qual a empresa é obrigada a remediar. São consideradas irreparáveis para o patrimônio e imagem da empresa. As perdas por desvalorização dos ativos devem ser demonstradas quando for possível o conhecimento ou estimativas de seus valores. Para o patrimônio da entidade e ao meio ambiente são consideradas irreparáveis e irremediáveis (PAIVA, 2009). 
Os indicadores de resíduos são importantes para a gestão do meio ambiente. Usa-se como base para estabelecer os indicadores a quantidade de resíduos medidos em quilogramas ou toneladas. Os resíduos podem ser designados à valorização ou eliminação. Como valorização estão os recicláveis, já os de eliminação estão aqueles que são destinados aos lixões (TINOCO \& KRAEMER, 2008).

A Tabela 2 demonstra os indicadores ambientais - emissão de resíduos dos períodos analisados.

Tabela 2 - Indicadores de desempenho ambientais - emissão de resíduos

\begin{tabular}{cccc}
\hline \multicolumn{4}{c}{ Emissão de dióxido de carbono (CO2) } \\
Os dados são dos relatórios 2010/2011 e 2011/2012 & Aumento/Redução \\
\hline & $\mathbf{2 0 1 0 / 2 0 1 1}$ & $\mathbf{2 0 1 1 / 2 0 1 2}$ & $1,16 \%$ \\
\hline $\begin{array}{c}\text { Quantidade de resíduos perigosos em t por } \\
\text { quantidade total de resíduos. }\end{array}$ & $24,30 \%$ & $25,46 \%$ & $(0,07 \mathrm{~m} 3)$ \\
\hline & Uso da água & $\mathbf{2 0 1 0 / 2 0 1 1}$ & $\mathbf{2 0 1 1 / 2 0 1 2}$ \\
\hline
\end{tabular}

Fonte: Da autora, adaptado de Paiva, 2009 - Dados relatório anual 2010/2011 e 2011/2012 da ETH

A tabela 3 evidencia os cálculos da proposição de eco-indicadores contábeis da empresa produtora de bioenergia, com base no Quadro 1.0 desse trabalho.

Tabela 3 - Cálculo da proposição de eco-indicadores contábil

\begin{tabular}{|c|c|c|c|c|}
\hline Formulação & $2010 / 2011$ & Indicador & 2011/2012 & Indicador \\
\hline $\begin{array}{c}1^{\mathrm{a}} \text { - Invest. em prevenção/ ativos } \\
\text { totais }\end{array}$ & $\begin{array}{c}1.661 .100,60 / \\
7.877 .456 .000,00\end{array}$ & 0,00021 & - & - \\
\hline $\begin{array}{c}5^{\mathrm{a}}-\text { Custos Ambientais/ Receitas } \\
\text { Operacionais }\end{array}$ & $\begin{array}{c}42.456 .142,00 / \\
1.113 .827 .000,00\end{array}$ & 0,4 & $\begin{array}{l}27.915 .400,00 / \\
1.783 .237 .027\end{array}$ & 0,2 \\
\hline $\begin{array}{c}6^{\mathrm{a}} \text { - Despesas Ambientais/ Receitas } \\
\text { Operacionais }\end{array}$ & $\begin{array}{c}15.000,00 / \\
1.113 .827 .000,00\end{array}$ & 0,000013 & $\begin{array}{c}68.400,00 / \\
1.783 .237 .027\end{array}$ & 0,00004 \\
\hline $\begin{array}{c}7^{\mathrm{a}} \text { - Gastos Totais com Prevenção/ } \\
\text { Valor Adicionado Total }\end{array}$ & $\begin{array}{l}24.877 .621,60 / \\
673.288 .000,00\end{array}$ & 0,037 & $\begin{array}{c}32.765 .200,00 / \\
994.530 .000,00\end{array}$ & 0,033 \\
\hline $\begin{array}{c}8^{\mathrm{a}} \text { - Gastos com Remediação/ Gastos } \\
\text { com prevenção }\end{array}$ & $\begin{array}{l}19.054 .621,00 / \\
24.877 .621,60\end{array}$ & 0,77 & $\begin{array}{c}0,00 / \\
32.765 .200,00\end{array}$ & 0,0 \\
\hline
\end{tabular}

\section{Apresentação e análise dos dados}

A elaboração de relatório anual com base nas diretrizes da GRI- Global Reporting Iniciative começou a partir do $4^{\circ}$ ano de existência, sendo o da safra 2010/2011. Em 2012 foi elaborado seu segundo relatório anual. Para a execução desse trabalho foram utilizados dados desses relatórios da empresa: 2010/2011 e 2011/2012, com base nos indicadores de desempenho ambientais. 


\subsection{Gastos com prevenção, remediação e irremediáveis}

Para quantificar os gastos ambientais de uma empresa é preciso primeiramente, segregá-los em três tipos: gastos com prevenção, remediação e irremediáveis. No primeiro relatório da safra 2010/2011 a empresa registrou um investimento com prevenção ambiental de R \$1.661.100,60, já no segundo o investimento foi de $\mathrm{R} \$ 4.849 .800,0$, com um aumento de $\mathrm{R} \$ 3.188 .699,40$. O custo com prevenção no primeiro relatório foi de $\mathrm{R} \$ 23.201 .521,00$; no segundo $\mathrm{R} \$ 27.168 .900,00$. No entanto, os custos com remediação no relatório 2010/2011 registraram $\mathrm{R} \$ 19.254 .621,00$; no período de 2011/2012 não teve nenhum registro (PAIVA, 2009; ETH, 2010/2011 e 2011/2012).

As despesas com prevenção no período 2010/2011, foram $\mathrm{R} \$ 15.000,00$; no período 2011/2012, totalizaram $\mathrm{R} \$ 68.400,00$. Não teve nenhum registro em despesas com remediação e nem com irremediáveis. Também não foram registrados em nenhum período, perdas (geração de novos passivos) e perdas (desvalorização de ativos) (PAIVA, 2009; ETH, 2010/2011 e 2011/2012).

\subsection{Indicadores de desempenho ambientais-emissão de resíduos}

Por meio dos indicadores de resíduos é possível identificar a porcentagem de resíduos que se destina à eliminação, ou seja, aquele que são destinados em lixões em relação aos resíduos totais, por exemplo. Aqui, foi feito um cálculo dos indicadores de resíduos, para encontrar a taxa de resíduos perigosos gerados pela empresa, utilizando a quantidade de resíduos perigosos em toneladas por quantidade total de resíduos. O resultado foi: $24,30 \%$ no período $2010 / 2011$ e $25,46 \%$ no período 2011/2012; isso significa que não houve diminuição, pelo contrário, aumentou 1,16\% na emissão de resíduos perigosos.

O consumo de água por tonelada de cana processada teve uma redução de $0,07 \mathrm{~m}^{3}$ no período de 2011/2012, sendo em 2010/2011 1,22 m³ de água por t de cana processada e 2011/2012 $1,15 \mathrm{~m}^{3}$ de água por $\mathrm{t}$ de cana processada.

\subsection{Proposição de eco-indicadores contábil}

Por meio do Quadro 1 de proposição de eco-indicadores contábeis foi possível encontrar alguns índices, utilizando fórmulas, os quais se apresentam na Tabela 3. A primeira fórmula identifica o quanto a empresa investe em questões ambientais, ou seja, indica a proporção entre ativos ambientais adquiridos no período e os ativos totais da empresa. No caso da empresa em questão foi calculado um índice de 0,00021 no período de 2010/2011. A segunda revela a evolução dos investimentos em prevenção em relação ao parque fabril, refletindo a preocupação com a qualidade de suas operações. Não foi possível calcular esse índice por falta de dados sobre os ativos imobilizados da empresa.

A terceira fórmula demonstra o percentual de diminuição do patrimônio em função de perdas ambientais, reflete o grau de cuidado com as operações, como o reflexo direto na alteração 
do patrimônio. Esse índice também não foi possível calcular, pois a empresa não apresentou perdas ambientais. A quarta fórmula, indica o quanto em termos percentuais, as perdas significaram sobre os bens e direitos que a empresa tinha no período, refletindo o grau de conscientização mediante catástrofes ambientais.

A quinta indica o quanto os custos ambientais apropriados no período representam das receitas operacionais, isso demonstra os investimentos da empresa na qualidade ambiental de seus produtos e como isso afeta seu resultado. O resultado em 2010/2011 foi um índice de 0,4; no período de 2011/2012 foram 0,2; isso significa que a empresa investe na qualidade ambiental de seus produtos.

A sexta fórmula, evidencia as despesas em prol do meio ambiente na geração de receitas operacionais, isso é interessante, pois revela a relação entre a conscientização da empresa e suas atividades de comercialização. O índice da empresa foi de 0,000013 e 2010/2011 e 0, 00004 em 2011/2012.

A penúltima fórmula relaciona os gastos em prevenção com o valor adicionado total, refletindo a posição da empresa em relação aos seus gastos na prevenção de problemas ambientais face ao valor adicionado por suas operações. O resultado calculado em 2010/2011 foi de 0,037; já em 2011/2012 o indicador calculado foi de 0,033, demonstrando assim os gastos em prevenção que a empresa desembolsou.

A oitava e última fórmula, indica a relação entre remediação e prevenção e revela a postura da empresa em sua relação com o meio ambiente. Esse índice mostra a postura da empresa em relação ao meio ambiente, em 2010/2011 o resultado foi de 0,77, no período de 2011/2012 esse índice foi 0,0 .

\subsection{Análise do estudo de caso}

O que se pode observar com as descrições acima é que a empresa tem consciência da importância de se ter práticas ambientais em seu processo operacional; mais do que isso, reconhece a importância de divulgar as ações ambientais, por meio de seus relatórios anuais.

De acordo com o relatório na safra 2011/2012, a ETH Bioenergia designou R \$ 32,8 milhões em investimentos e gastos em proteção ambiental, um aumento de 45,2\%, comparado ao ano anterior que foi de $\mathrm{R} \$ 21,5$ milhões.

É notório que a empresa teve um aumento na produção de 2010/2012 comparado ao período anterior, como: na produção de etanol que teve um aumento de 39,6\%; na produção de açúcar 24,6\%; produção de energia um aumento de $275 \%$. Todo esse aumento na produtividade da empresa tem relação com o acréscimo no investimento e nos gastos ambientais. 
Em relação aos resíduos gerados pela empresa, houve uma diminuição em 2011/2012 se comparado ao período anterior, quanto aos resíduos não perigosos, ou seja, aqueles destinados aos aterros e lixões: a redução foi de 50\%, o que só foi possível devido à adoção de sistemas de coleta seletiva e da pasta de compostagem feita pela empresa. Já nos resíduos perigosos a redução foi de $13,7 \%$ representando 872,6 toneladas, sendo $100 \%$ tratados e reaproveitados. Como foi dito anteriormente, a taxa de resíduos perigosos foi de 32,09\% no período 2010/2011 e 25,46\% no período 2011/2012, uma redução de 6,63\%.

Ocorreu uma redução no consumo de água por tonelada de cana processada de 1,22 $\mathrm{m}^{3}$ para $1,15 \mathrm{~m}^{3}$.

\section{Conclusão}

Esse trabalho teve como objetivo evidenciar os gastos ambientais de uma empresa produtora de bioenergia, a ETH Bioenergia, mostrando suas ações e práticas ambientais.

Por meio de dados disponibilizados em relatório da empresa foi possível calcular alguns indicadores de desempenho ambientais, utilizando-se de pesquisa documental, exploratória e qualiquantitativa.

De acordo com o relatório na safra 2011/2012, a ETH Bioenergia designou R \$ 32,8 milhões em investimentos e gastos em proteção ambiental, um aumento de 45,2\%, comparado ao ano anterior que foi de $\mathrm{R} \$ 21,5$ milhões.

É notório que a empresa teve um aumento na produção de 2010/2012 comparado ao período anterior, como: na produção de etanol que teve um aumento de 39,6\%; na produção de açúcar 24,6\%; produção de energia um aumento de $275 \%$. Todo esse aumento na produtividade da empresa tem relação com o acréscimo no investimento e nos gastos ambientais.

Considera-se que os objetivos específicos da pesquisa foram alcançados, visto que, como observado, a evidenciação de gastos ambientais é uma aliada importante para construir ou melhorar a imagem de uma empresa perante o mercado e a sociedade, que cada vez mais, tornam-se exigentes. Porém, isso não será possível se a empresa não tiver uma contabilidade ambiental que forneça informações úteis para a tomada de decisão em fatos ambientais.

Portanto, além de melhorar a imagem, como foi dito, a evidenciação ajuda a empresa a divulgar os requisitos ambientais necessários, para ser inserida no mercado mundial, ou seja, alcançar vantagens competitivas no mercado, atraindo novos negócios e conquistando novos consumidores.

Como sugestão para trabalhos futuros, sugere-se uma pesquisa de comparação entre empresas do ramo de bioenergia para verificar se estas estão se mantendo competitivas ao adotarem práticas de sustentabilidade. 


\begin{abstract}
This work aimed to highlight the environmental costs of a company producing bioenergy in order to demonstrate the degree of awareness and concern about the environment, and emphasize the importance of environmental accounting in the identification, recording and measurement of facts environmental company. In this work we used the method of documentary research, exploratory and qualitative and quantitative. Using data available in the company's report studied was possible to calculate some indicators of environmental performance, as the research instrument was based on data analysis of indicators. As noted, the disclosure of environmental expenditures is an important ally to build or improve the image of a company to the market and society, which increasingly become demanding. However, this will not be possible if the company does not have an environmental accounting to provide information useful for decision making, especially in relation to the environment.
\end{abstract}

Keywords: environmental accounting; environmental performance indicators; bioenergy.

\title{
Referências
}

BORGES, A. P.; ROSA, F. S. da; ENSSLIN, S. R. Evidenciação voluntária das práticas ambientais: um estudo nas grandes empresas brasileiras de papel e celulose. Revista produção. v. 20, n. 3, p. 404-417, 2010.

CASTRO, N. J.; DANTAS, G. de A. Bioenergia no Brasil e na Europa: uma análise comparativa. Rio de Janeiro, 2008.

CUNHA, A. M. et al. Contabilidade ambiental e demonstrações financeiras obrigatórias: informações ambientais relevantes nas notas explicativas. Seminários em Administração- (XIII SEMEAD). Disponível em http://www.ead.fea.usp.br/semead/13semead/resultado/trabalhosPDF/903.pdf. Acesso em 02 out. 2012.

ETH. Relatório Anual da ETH 2010/2011 e 2011/2012. Disponível em < http://www.odebrechtagroindustrial.com/> Acesso em 04 out. 2012.

FERREIRA, A. C. de S. Contabilidade ambiental: uma informação para o desenvolvimento sustentável. 2. ed. São Paulo: Atlas, 2009.

Global Reporting Iniciative - GRI. Diretrizes para Relatórios de Sustentabilidade. 2000-2006. Disponível em http://www.globalrepotring.org. Acesso em 05 out. 2012.

LIMA, J. P. C., et al. Estudo de caso e sua aplicação: Proposta de um esquema teórico para pesquisas no campo de contabilidade. Revista de Contabilidade e Organizações, vol. 6 n. 14 (2012) p. 127-144. crossref

MOREIRA, R. Bioenergia, sentido e significado. Revista da ANPEGE. v. 3, p.43, 2007.

PAIVA, P. R. Contabilidade ambiental: evidenciação dos gastos ambientais com transparência e focada na prevenção. São Paulo: Atlas, 2009.

RIBEIRO, M. de S. O tratamento contábil dos créditos de carbono. Ribeirão Preto, 2005.90 p. Tese de livre docência apresentada à Faculdade de Economia, Administração e Contabilidade, campus de Ribeirão Preto/USPDepartamento de contabilidade.

SANTOS, A. O. et al. Contabilidade ambiental: um estudo sobre sua aplicabilidade em empresas brasileiras. Revista de Contabilidade \& Finanças da Fipecafi, n. 27, p. 89, 2001.

SCARPIN, J. E. et al. Entendimento e ações do profissional contabilista perante o mundo sustentável. Seminários em Administração- (XI SEMEAD). Disponível em

http://www.ead.fea.usp.br/semead/11semead/resultado/an_indicearea.asp?letra=E\&pagina=2 Acesso em 02 out. 2012.

SOUZA, A. P. Mecanismos fotossintéticos e relação fonte-dreno em cana de açúcar cultivada em atmosfera enriquecida em CO2. 2011. São Paulo, Tese (Doutorado)- Instituto de Biociências da Universidade de São Paulo, Departamento de botânica. 208p. 
TINOCO, J. E. P.; KRAEMER, Maria Elizabeth. Contabilidade e Gestão ambiental. 2. ed. São Paulo: Atlas, 2008.

VIAN, C. E. F.; RIBEIRO, F. A. Bioenergia uma análise comparada entre as políticas para o etanol e o biodiesel e de suas perspectivas. XLVI Congresso da Sociedade Brasileira de Economia, Administração e Sociologia Rural. (SOBER), Julho, 2008.

\section{Dados dos autores}

Nome completo: Graciela Arcanjo da Costa

Filiação institucional: Universidade Federal da Grande Dourados - UFGD

Função ou cargo ocupado: Graduada em Ciências Contábeis

Endereço completo para correspondência (bairro, cidade, estado, país e CEP): Rod. Dourados Itahum, Km 12, Cx. Postal 322, Dourados - MS. CEP: 79.825-070

e-mail: cielyarcanjo@ hotmail.com

Nome completo: Maria Aparecida Farias de Souza Nogueira

Filiação institucional: Universidade Federal da Grande Dourados- UFGD

Função ou cargo ocupado: Graduada em Ciências Contábeis - UFMS, Especialização em Contabilidade Gerencial - UFMS, Especialização em Gestão Pública - UFMS; Mestre em Agronegócios pela UFMS.

Professora Assistente da, lotada na Faculdade de Administração, Contábeis e Economia - FACE Endereço completo para correspondência (bairro, cidade, estado, país e CEP): Rod. Dourados Itahum, Km 12, Cx. Postal 322, Dourados - MS. CEP: 79.825-070

Telefones para contato: Telefone: (67) 3410-2040/6.

e-mail: marianogueira@ufgd.edu.br

Nome completo: Marli da Silva Garcia

Filiação institucional: Universidade Federal da Grande Dourados- UFGD

Função ou cargo ocupado: Graduação em Administração de Empresas. Especialização em Metodologia do Ensino Superior - Mestre em Gestão e Produção Agroindustrial.

Endereço completo para correspondência (bairro, cidade, estado, país e CEP): End.: Rua Ciro Melo, 5060. Jd. Eldorado. Dourados - MS. CEP: 79830-050

Telefones para contato: Telefone: (67) 9925-8833

e-mail: marliggarcia@gmail.com

Submetido em: 01/11/2013

Aceito em: 02/10/2014 